\title{
Mothers Against Decapentaplegic Homolog 5
}

National Cancer Institute

\section{Source}

National Cancer Institute. Mothers Against Decapentaplegic Homolog 5. NCI Thesaurus. Code C118587.

Mothers against decapentaplegic homolog 5 (465 aa, $\sim 52 \mathrm{kDa}$ ) is encoded by the human SMAD5 gene. This protein is involved in transcriptional regulation mediated by receptor signaling. 